\title{
Treatment of lipid keratopathy with the argon laser
}

\author{
R. J. MARSH AND J. MARSHALL \\ From the Western Ophthalmic Hospital and the Institute of Ophthalmology, London
}

SUMmaRY Twenty-two patients with lipid keratopathy were treated with argon laser photocoagulation to the feeder vessels. Two were grafted just over a week after treatment and the corneal discs examined histologically. The remainder of the patients were followed up for at least a year. In 6 cases the visual acuity improved, in 3 deteriorated, and in 10 did not change. The density and extent of the lipid deposition were diminished in $50 \%$ of cases. The commonest complications were bleeding into the lipid keratopathy and iris damage. The only serious problem was a disciform type of lipid keratopathy that flared up after treatment. Suggestions are made on improvements in the technique of laser application.

Many patients with chronic corneal inflammatory disease are left with a vascularised scar and secondary lipid deposition. Not only is this unsightly, but it may spread across the pupil, diminishing vision and causing troublesome photophobia. Treatment may be considered under 2 main headings: primary preventive and secondary measures to deal with established disease. Primary measures include adequate early treatment of keratitis to prevent infiltration and vascularisation-for example, adequate long-term topical steroid administration in herpes simplex and zoster keratitis (with suitable antiviral cover in the former) - and the investigation and treatment of any systemic lipid anomaly. Established lipid keratopathy is more of a problem. Direct removal of superficial deposits may be attempted by keratectomy, but, when they are deeper, lamellar or penetrating corneal grafting is necessary.

Obviously the results of grafting are particularly poor in a vascularised host. Much attention has been concentrated in the past on the occlusion of these new vessels in the hope that further lipid deposition may be prevented, some resorption occur, and the host made safer for grafting. The methods have included peritomy, severing or cautery of the vessels at the limbus, ${ }^{1} \beta$ radiation, ${ }^{2-6}$ thiotepa, ${ }^{78}$ and cryotherapy. ${ }^{9}$ All these methods were assessed by Ey et al. ${ }^{1}$ in the inhibition of induced vascularisation in rabbits, and they found the most effective were $\beta$ radiation, thiotepa, and topical steroid. The latter is known to reduce cellular infiltration, diminish fibroplastic

Correspondence to R. I. Marsh. FRCS. Western Ophthalmic Hospital. Marylebone Road. London NW1. repair and postinflammatory vascularisation, and reduce capillary permeability associated with inflammation of the cornea. ${ }^{10-12}$ More recently, renewed attempts have been made to occlude the new vessels unresponsive to steroid with the argon laser. ${ }^{13-15}$ Cherry et al.${ }^{13}$ treated 4 patients with lipid keratopathy and had a short-term success in closure of new vessels in all cases, but regrowth occurred in 3 patients after 6 months. We felt that by modifying the technique used for closure of small new vessels in diabetic retinopathy ${ }^{16}$ we might have something useful for early cases of keratopathy, further lipid deposits being prevented and existing lipid absorbed by macrophages passing into adjacent corneal lymphatics. However, in the more advanced cases we recognised that major irreversible structural changes had occurred in the cornea and that full recovery would be impossible.

We proposed to give due consideration to possible dangers to iris, lens, and retina during the trial. We decided to try to obtain the discs from patients grafted soon after corneal lasering.

\section{Materials and methods}

Patients with all degrees of lipid keratopathy were drawn on a voluntary basis from those attending the Western Ophthalmic Hospital and Moorfields Eye Hospital. A history and full examination were carried out and the following recorded: history and aetiology of keratitis, drug treatment, visual acuity, the extent, density, and vascularisation of lipid deposits, iris appearance, and lens clarity. They were reassessed every 3-6 months, and most patients were screened for any systemic lipid anomalies. 
Colour photographs were taken on the photo slitlamp every 6 months at $\times 2$ magnification with identical settings, lighting conditions, and film. A careful grading was made on the density and extent of lipid deposits. Density was recorded as mild, moderate, or severe, and the extent was expressed as a fraction of the total area of the cornea. Corneal fluorescein angiography was carried out on all patients prior to treatment and thereafter every 6 months to 1 year. Vascularisation was scored as mild, moderate, or severe and a note added on the size of the stem. Earlier patients were recorded at $\times 1$ magnification on $35 \mathrm{~mm}$ film but later at $\times 2$ magnification on film and videotape by the technique described by Marsh and Ford. ${ }^{17}$ The videotape was particularly useful because it could be immediately and repeatedly replayed to identify vascular filling pattern and closure.

Prior to treatment with a coherent radiation 900 argon laser $1 \%$ amethocaine was instilled; the patient was cautioned to be very still and stare constantly at the fixation light. To a certain extent the instrument settings and technique varied and underwent evolution as we progressed. The aperture setting varied from $50 \mu \mathrm{m}$ to $100 \mu \mathrm{m}$ depending on the size of the vessels to be treated, but it was important to have the machine checked regularly for correct focusing of the beam. The intensity necessary to occlude the blood column varied from 0.2 to 0.8 watts and again depended on the state of repair of the machine, although we found it better to start at a low level and slowly increase. We used $0 \cdot 1 \mathrm{~s}$ exposures, the slowest speed possible consistent with comfort. The illumination of the slit was kept as low as possible and the delivery system angled to the cornea so that rays were directed away from the pupil to the periphery of the iris. It was best to constrict the pupil prior to treatment.

We preferred to begin treatment just behind the limbus, occluding all the main feeder tracks seen on the angiograms (this tended to 'trap' blood columns in the cornea). Next we occluded the main veins, just corneal to the limbus, which expanded and darkened these columns, facilitating further photocoagulation. They were progressively closed or blackened towards the centre of the cornea. After we closed the large veins we returned to the larger arteries in which flow had been considerably slowed. Smaller aperture settings and more power were necessary to close them all along their course. We next tackled any remaining small vessels and found it best to treat them initially at 'cross-over' points and then fill in intermediate sections.

All treatments were recorded. We found it best to arrange 3 treatment sessions in a day owing to the tendency of anastomotic channels to open up $1 / 2-1$ hour after initial laser treatment. So we started early in the morning, and applied the second at midday and the last in the late afternoon. In cases of profuse vascularisation patients were initially brought back for treatment every 2 weeks. As successful closure was achieved patients returned approximately every 3 months for assessment, including repeat of angiography and further treatment as necessary.

Efficacy of treatment was judged by improvement in visual acuity, a reduction in density and extent of the lipid, and by disappearance of vascularisation. Thus, these details were carefully recorded at each visit and photographed. In 2 cases histology was obtained after laser application.

Case 1 was a 27-year-old man with a history of keratitis and dense vascularised central lipid keratopathy. Photographs and angiogram were taken and laser was applied to the vessels. Ten days later a corneal penetrating graft was carried out with immediate transfer of the disc to fixative.

Case 2 was a 30-year-old man with a history of keratitis and dense vascularised central lipid keratopathy. Photographs and angiogram were taken and laser was applied to the vessels. Eleven days later a penetrating graft was carried out with immediate transfer of the disc to refrigerated fixative.

Both discs were fixed for at least 1 hour in $2.5 \%$ gluteraldehyde buffered in $0 \cdot 1 \mathrm{M}$ sodium cacodylate containing $10 \mathrm{mg} / \mathrm{ml}$ calcium chloride and with a final $\mathrm{pH} 7 \cdot 4$. After initial fixation each disc was briefly washed in cacodylate buffer containing $7.5 \%$ sucrose, and the areas exposed to laser irradiation were then isolated under a dissecting microscope. Samples of irradiated and unirradiated areas of both discs were postfixed for 1 hour in $2 \%$ osmium tetroxide in $0.2 \mathrm{M}$ sodium cacodylate, dehydrated through a graded series of ethanol concentrations in water, and then embedded in Epon via epoxypropane. Semithin sections $(0 \cdot 75-1 \mu \mathrm{m}$ thick) were cut on glass knives and stained with alcoholic toluidine blue.

\section{Results}

Twenty-two patients were treated with laser and of them 19 were followed up for a minimal period of a year. One patient failed follow-up after 3 months and 2 received corneal transplants 1 week after treatment.

The keratopathies could be broadly classified by morphology into several types: $(a)$ central; $(b)$ eccentric disciform; (c) marginal; (d) diffuse interstitial; and $(e)$ diffuse deep. Table 1 shows the distribution of patients to these groups and their aetiology.

Table 2 shows the results of treatment in the 19 patients with minimum follow-up of 1 year. It can be seen that there was improvement in visual acuity in 6 cases, deterioration in 3 , but no change in 10 . The density of the lipid was reduced in 9 cases, increased 
Table 1 Distribution of keratopathy

\begin{tabular}{llllll}
\hline Aetiology & $\begin{array}{l}\text { Central } \\
\text { disciform }\end{array}$ & $\begin{array}{l}\text { Eccentric } \\
\text { disciform }\end{array}$ & Marginal & $\begin{array}{l}\text { Diffuse } \\
\text { interstitial }\end{array}$ & $\begin{array}{l}\text { Diffuse } \\
\text { deep }\end{array}$ \\
\hline HS & 4 & 5 & 2 & 1 & \\
HZ & 1 & 1 & & & \\
Rosacea & 0 & 1 & & & \\
Trauma & 0 & 1 & & & 2 \\
Idiopathic & 0 & 1 & & & \\
\hline
\end{tabular}

HS = herpes simplex. $\mathrm{HZ}=$ herpes zoster.

in 3 , but remained the same in 7 . The extent of the lipid was reduced in 11 , increased in 1 , and there was no change in 7 . Recurrence of vessels was troublesome in 7 , easily handled in 4 , and not a problem in 8 .

\section{COMPLICATIONS}

During lasering 6 patients developed peaking of the pupil and 7 bled into the area of keratopathy. Both of these complications had usually resolved after 2 weeks and seemed not to lead to any serious long-term problems. Most patients tolerated the treatment very well, though some found fixating difficult. Occasion- ally, when a large vessel near the surface was treated, a hole was punched out of the overlying cornea, through which blood found its way to the surface. However, these lesions healed very well over the following days. Great care was taken to avoid hitting the iris, but it was impossible to achieve this at all times. When it was hit several reactions occurred depending on the strength and siting of the shot. Firstly, nothing appeared to happen; secondly, a sudden spurt of cells and debris appeared in the adjacent aqueous drifting upwards, often accompanied by the production of an air bubble on the iris and a faint popping sound. If a major radial artery to the sphincter was hit peaking occurred.

The commonest late complication occurring in nearly all cases was iris atrophy. This obviously lay under the treated area and was chiefly stromal. The pigment epithelium was visibly breached in a few cases only. In 2 the pupil was permanently peaked. These complications rarely gave rise to a visual or cosmetic problem. There was no biomicroscopically observable lens defect as a result of treatment in any of the cases (the longest follow-up period being 5 years). So far as we are aware, the retina was not

Table 2 Results of laser therapy in 19 cases of lipid keratopathy

\begin{tabular}{|c|c|c|c|c|c|c|c|c|c|c|}
\hline Case & $\begin{array}{l}\text { Distribution of } \\
\text { lipid }\end{array}$ & Density & $\begin{array}{l}\text { Extent } \\
\text { of } \\
\text { cornea }\end{array}$ & Vascularity & Stem & $\begin{array}{l}\text { Amounts } \\
\text { of laser } \\
\text { (sittings) }\end{array}$ & Density & Extent & $\begin{array}{l}\text { Visual acuity } \\
\text { (Snellen's) }\end{array}$ & Vascularity \\
\hline 1 & Marginal & Mild & $1 / 9$ & Mild & Several & $114(2)$ & Less & Less & Same & A little recurrence \\
\hline 2 & $\begin{array}{l}\text { Marginal graft } \\
\text { Host junction }\end{array}$ & Moderate & $1 / 10$ & Moderate & Narrow & $1154(3)$ & $\begin{array}{r}\text { Much } \\
\text { less }\end{array}$ & Much less & Same & $\begin{array}{l}\text { No recurrence } \\
\text { (Fig. 1) }\end{array}$ \\
\hline 3 & $\begin{array}{l}\text { Graft host } \\
\text { junction }\end{array}$ & Moderate & $1 / 8$ & Moderate & Narrow & $868(3)$ & Less & Same & Same & Minimal recurrence \\
\hline 4 & $\begin{array}{l}\text { Eccentric } \\
\text { disciform }\end{array}$ & Severe & $1 / 3$ & Moderate & Several & $4023(14)$ & Less & Less & Same & Constant recurrence \\
\hline 5 & $\begin{array}{l}\text { Eccentric } \\
\text { disciform }\end{array}$ & Severe & $1 / 2$ & Moderate & Multiple & $2411(5)$ & Same & Same & Same & Constant recurrence \\
\hline 6 & $\begin{array}{l}\text { Failed follow-up } \\
\text { at } 3 \text { months }\end{array}$ & & & & & & & & & \\
\hline 7 & $\begin{array}{l}\text { Eccentric } \\
\text { disciform }\end{array}$ & Moderate & $1 / 4$ & Profuse & Broad & $891(1)$ & Less & Less & Same & Some recurrence \\
\hline 8 & $\begin{array}{l}\text { Eccentric } \\
\text { disciform }\end{array}$ & Moderate & $1 / 6$ & Mild & Narrow & $68(2)$ & $\begin{array}{r}\text { Much } \\
\text { less }\end{array}$ & Much less & Improved & $\begin{array}{l}\text { Minimal recurrence } \\
\text { (Fig. 2) }\end{array}$ \\
\hline 9 & $\begin{array}{l}\text { Eccentric } \\
\text { disciform }\end{array}$ & Moderate & $1 / 2$ & Moderate & Narrow & $859(3)$ & $\begin{array}{r}\text { Much } \\
\text { less }\end{array}$ & Much less & Improved & Minimal recurrence \\
\hline 10 & $\begin{array}{l}\text { Eccentric } \\
\text { disciform }\end{array}$ & Severe & $1 / 4$ & Moderate & Narrow & $577(2)$ & Same & Same & Same & Some recurrence \\
\hline 11 & $\begin{array}{l}\text { Eccentric } \\
\text { disciform }\end{array}$ & Severe & $1 / 4$ & Moderate & Several & $2562(4)$ & Same & Less & $\begin{array}{l}\text { Slightly } \\
\text { improved }\end{array}$ & Minimal recurrence \\
\hline 12 & $\begin{array}{l}\text { Eccentric } \\
\text { disciform }\end{array}$ & Severe & $1 / 3$ & Moderate & Several & $2180(4)$ & $\begin{array}{l}\text { Slightly } \\
\text { less }\end{array}$ & Less & Same & Minimal recurrence \\
\hline 13 & Central disciform & Moderate & $1 / 4$ & Moderate & Multiple & $9417(14)$ & Worse & Worse & Worse & Constant recurrence \\
\hline 14 & Central disciform & Severe & $1 / 4$ & Moderate & Narrow & $331(2)$ & Worse & Same & Same & Constant recurrence \\
\hline 15 & Central disciform & Severe & $1 / 6$ & Moderate & Several & $1865(3)$ & Same & Less & Same & Minimal recurrence \\
\hline 16 & Central disciform & Severe & $1 / 3$ & Profuse & Narrow & $2592(5)$ & Worse & Same & Worse & Constant recurrence \\
\hline 17 & Central disciform & Moderate & $1 / 6$ & Moderate & Multiple & $3302(7)$ & Same & Less & Worse & Some recurrence \\
\hline 18 & Deep diffuse & Mild & $1 / 4$ & Moderate & Narrow & $704(4)$ & Same & Same & Better & Some recurrence \\
\hline 19 & Deep diffuse & Mild & $1 / 4$ & Profuse & Narrow & $2791(5)$ & Same & Same & Better & Some recurrence \\
\hline 20) & Superficial diffuse & Severe & $1 / 2$ & Profuse & Multiple & $9889(13)$ & $\begin{array}{r}\text { Much } \\
\text { less }\end{array}$ & Less & Better & Constant recurrence \\
\hline
\end{tabular}


struck, though this was difficult to assess in some patients with dense opacities.

Two cases got obviously worse after treatment, and both were severe disciform types. The first, however, lost most of his vascularisation and was successfully grafted after 3 years. The second, unfortunately, developed a very serious disciform keratitis. This was partly accounted for by his failure to take his steroid drops after treatment, and his scarring became very dense.

\section{HISTOPATHOLOGY}

Both cases showed a similar distribution of vessels in the peripheral cornea with the anterior two-thirds of the stroma predominantly involved. Also in both patients the stromal lamellae were irregular, and centrally a marked erosion of this layer had occurred, resulting in a total central corneal thickness in case 1 of only $280 \mu \mathrm{m}$. Descemet's membrane was abnormally thick for individuals in their late 20 s, and in some areas discrete deposits of lipid were observed within this structure close to its anterior surface (Fig. $1 \mathrm{e}, \mathrm{f})$. The endothelium in these specimens appeared relatively normal, but macrophages were often observed in contact with its aqueous aspect.

The interpretation of the irradiated areas is complicated by the secondary tissue reactions that have occurred during the postexposure periods. The most significant changes were observed in the more superficial layers of the stroma. The topography of the damage would suggest a highly localised primary damage site associated with limited heat flow from the vessels that absorbed laser irradiation. However, the lamellar structure of the stroma, with vast regions of extracellular collagen, results in an amplification of secondary tissue responses, with tissue displacement through the presence of oedema and macrophages.

Two types of reaction were seen associated with blood vessels in the superficial stroma, namely, haemorrhages (Fig. 2) and blood stasis in areas of capillary closure (Fig. 2). Many areas of haemorrhages were observed, and these were presumably coincident with certain areas of irradiation. The haemorrhages were of various sizes, and haemolysing red blood cells could often be seen in the abnormally distended spaces between adjacent lamellae. Blood cells were particularly prominent in the region of Bowman's membrane and were often found between this layer and the basal cells of the epithelium. In many areas the disruptive effects of blood cells, macrophages, and oedema had resulted in gross distortions of the regular array of the basal cells such that they resembled those in the limbus (Fig. 3). In other areas the distortion was so gross that islands of epithelial cells were observed deep within the stroma, and some were undergoing division here.

Only 2 areas were found with incompletely healed epithelial erosions, which suggested that significant bleeding to the surface of this cornea was rare and that most sites were repaired within 10 days of exposure.

Vessels showing blood stasis with haemolysing blood cells and areas of capillary closure were usually less superficial and did not have changes in the adjacent tissues that would suggest that they were sites of irradiation. These changes in deeper vessels were probably due to interrupted flow in feeder or drainage systems. Many of these vessels were surrounded by macrophages and were abnormally swollen, both of which reactions caused further distortion of the adjacent lamellae.

In all areas where oedema and macrophages were present, but especially in the superficial layers, active keratocytes were also observed, and most of these had the rounded appearance of embryonic cells.

\section{Discussion}

We achieved some success in reducing the extent and density of the keratopathies. As expected, the early milder and marginal cases did best. The very advanced central types were devascularised, however, and made easier for grafting. We were very heartened by the one diffuse dense superficial keratitis which improved considerably. Aside from the small number

Fig. 1a, b Preoperative photograph and angiogram of patient 2 with lipid deposit at graft host junction. c, d Postlaser photograph and angiogram of patient 2 one year later. $\mathrm{e}, \mathrm{f}$ Light micrograph of central cornea showing erosion of stroma and the presence of both neovascular complexes and lipid deposits. The marker is $100 \mu \mathrm{m}$. High-power light micrograph of the posterior cornea in le showing lipid deposits within Descemet's membrane and a macrograph in contact with the endothelium. The marker is $10 \mu \mathrm{m}$.

Fig. 2a, b Preoperative photograph and angiogram of patient 7 with lipid deposition in eccentric disciform keratitis. c, $\mathrm{d}$ Postlaser photograph and angiogram of patient 7 one year later. e Light micrograph of the anterior cornea showing the presence of red blood cells within the stroma resulting from small haemorrhages, and red cell packing in non perfused vessels (arrowed). The marker is $50 \mu \mathrm{m}$.

Fig. 3a, b Light micrograph of anterior cornea showing distortion of Bowman's membrane and the presence of numerous red blood cells trapped between the stromal lamellae. Light micrographs of both an occluded (arrowed) and (c) reopened (arrowed) vessel in case 1, both showing the presence of red blood cells between the lamellae of the adjacent stroma. The marker is $25 \mu \mathrm{m}$. 

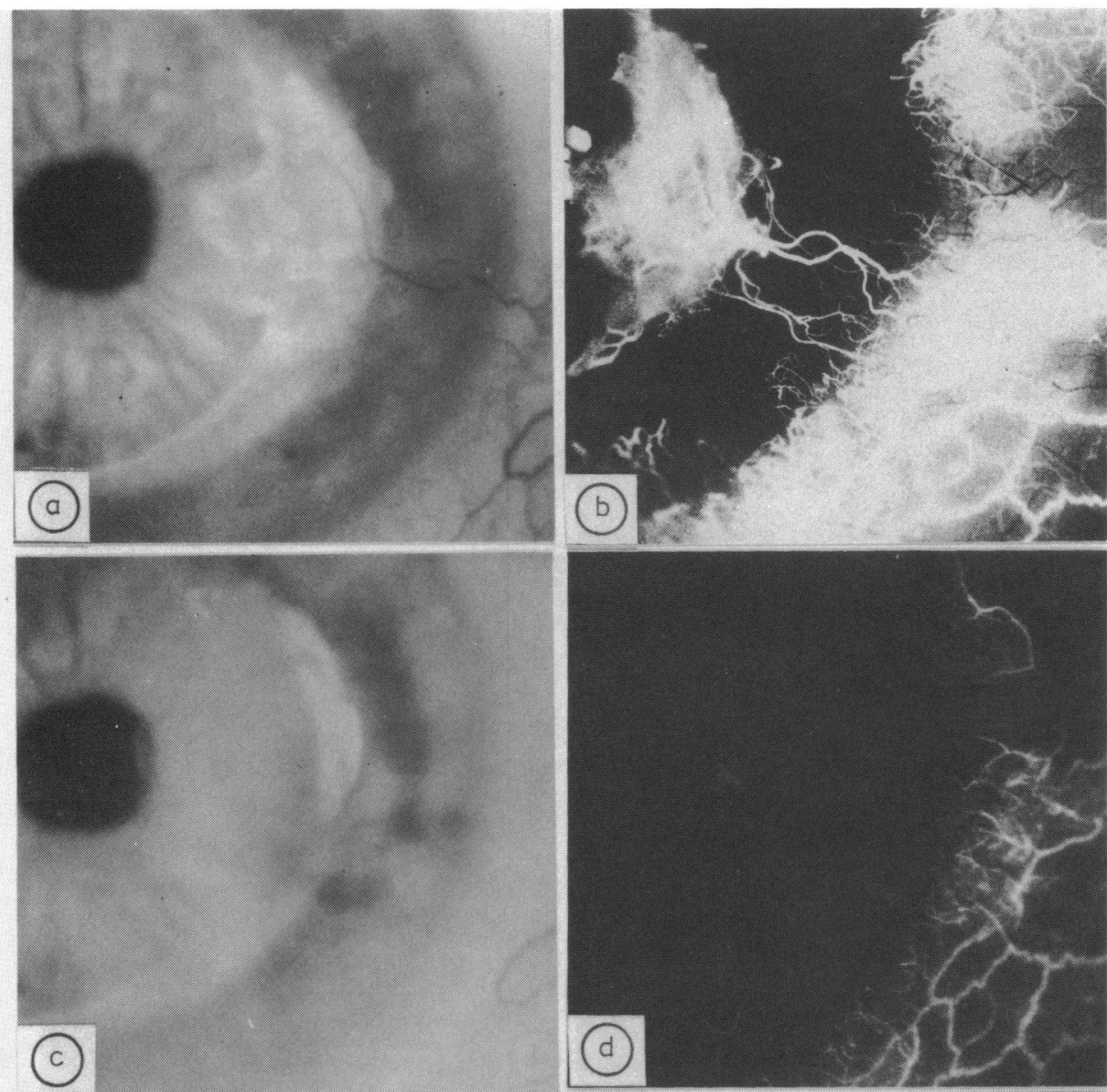

두

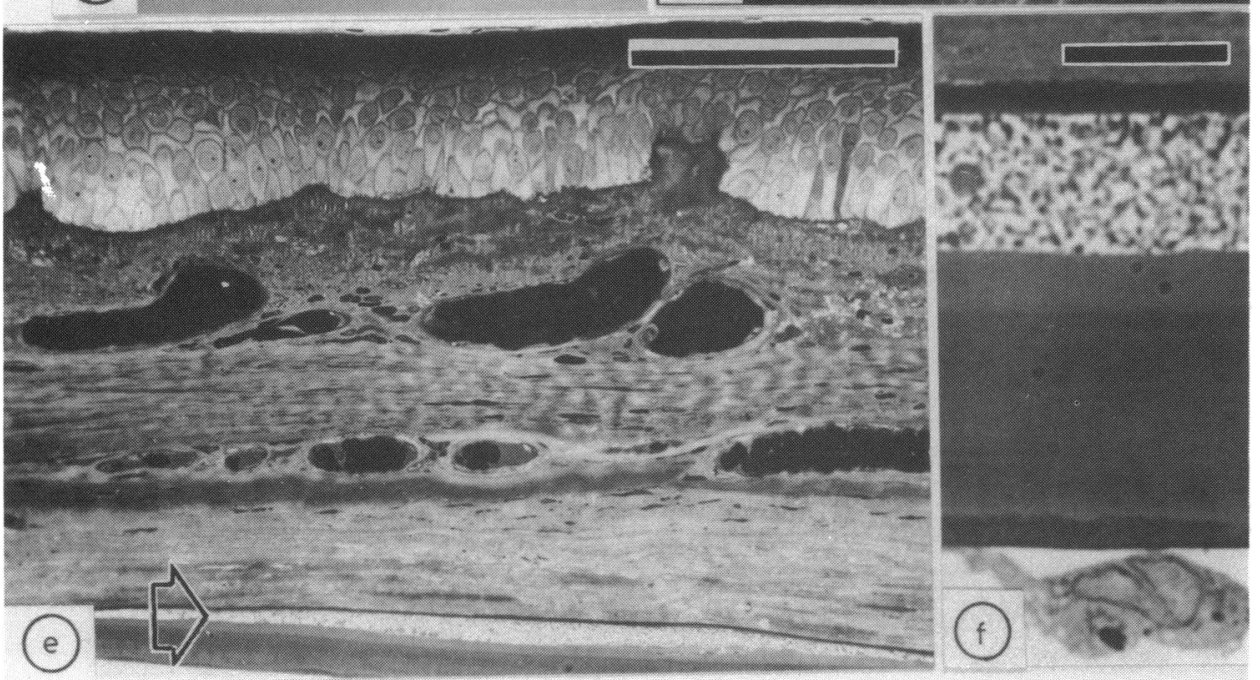

Fig. 1 

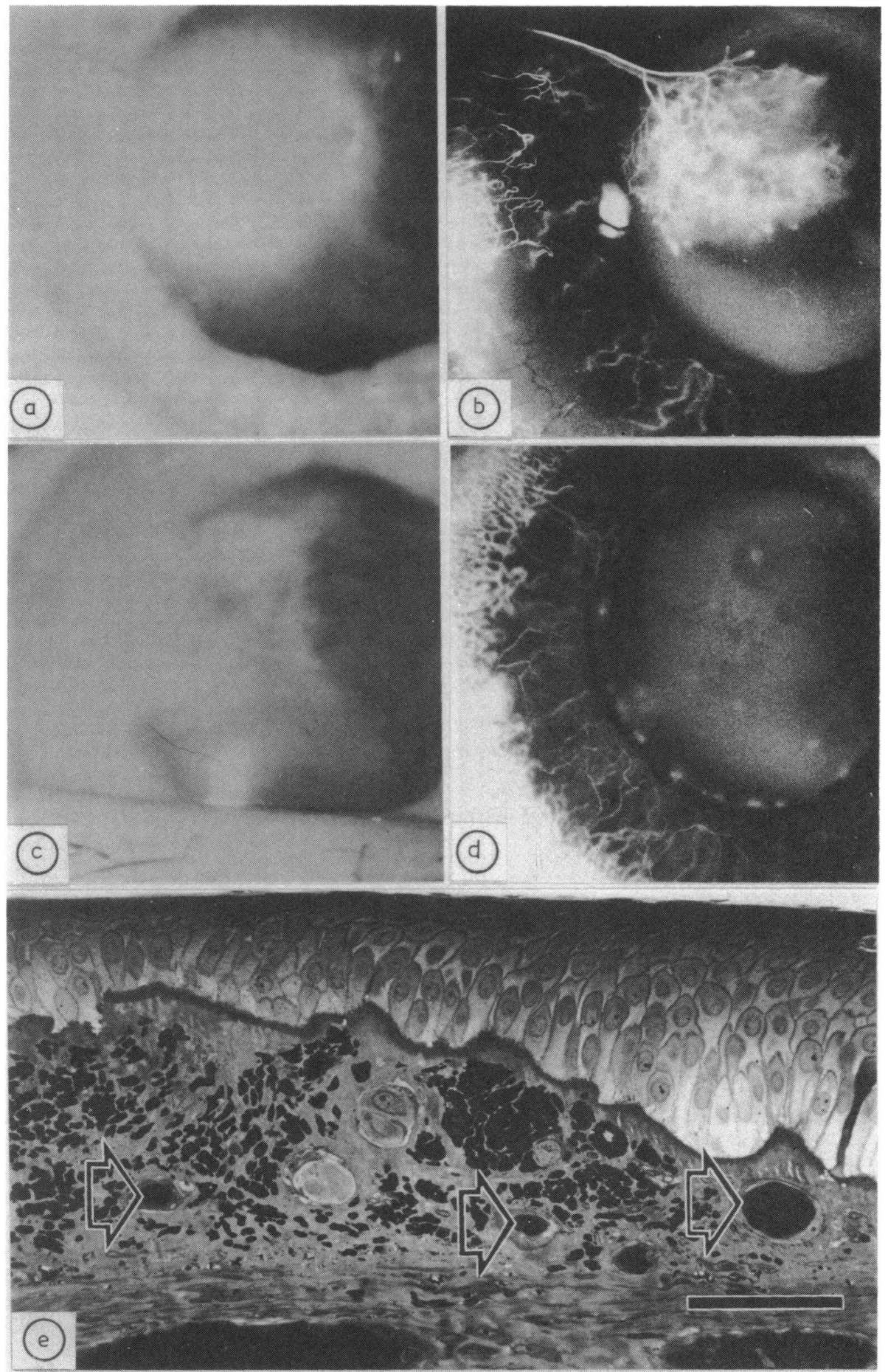

Fig ? 


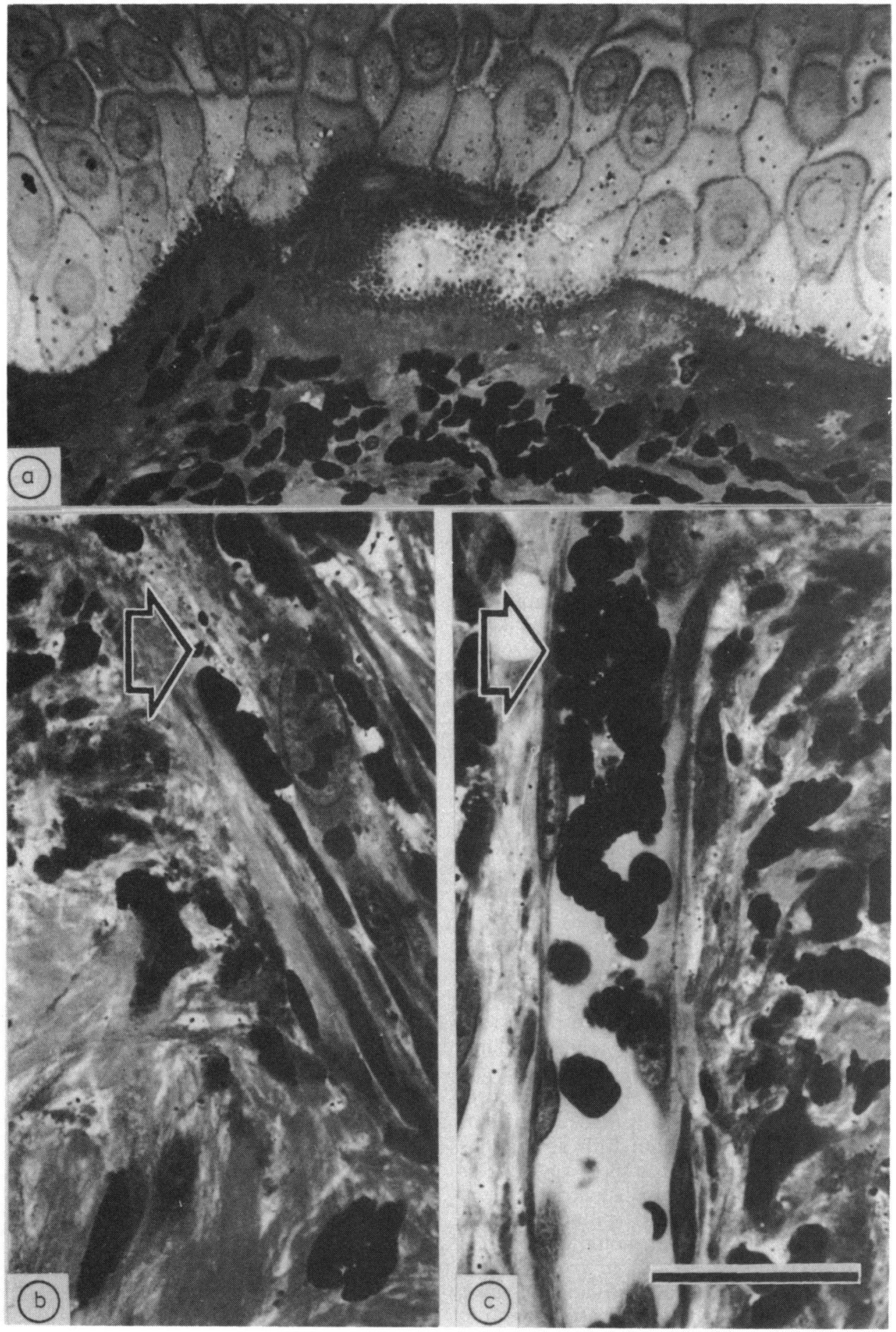

Fig. 3 
of cases with improved Snellen's visual acuity many were subjectively better and their symptoms of photophobia improved. It is also notable that a large number failed to progress, contrary to the normal natural history.

The mechanisms of laser-induced vascular occlusion are not fully understood, and elucidation of this problem was not an objective of the present investigation. However, in general our observations support the conclusions drawn from similar studies on argon laser irradiation of retinal vessels. ${ }^{18}$ In essence, whatever the secondary mechanisms of vessel closure, they are dependent upon absorption and degradation of laser energy by haemoglobin. The focal irradiance on the vessels must be high to deposit sufficient energy within them to achieve damaging thermal profiles at the vessel wall. Thus attempts to close capillaries with $120 \mu \mathrm{m}$ spot size exposures were always unsuccessful, because the area absorbing was always too small a portion of the total area irradiated. Once sufficient energy had been deposited within an irradiated vessel to induce temporary blood stasis further coagulation became relatively easier, because the cooling effect of flowing blood was lost. However, we found in our study, as in previous investigations, capillaries remained patent in areas of irradiation even when extensive necrosis of the capillary wall had occurred. Moreover evidence of intracapillary thrombosis and true fibrin deposition was rare, while small haemorrhages were common. Until detailed investigations of thermally induced occlusive processes are undertaken to optimise the required effect such surgical procedures remain empirical and depend upon the experience of the surgeon.

We are clearly concerned about the complications. Corneal transmission of short argon lines of emission is poor; thus dissipation in the cornea may be harmful. ${ }^{19}$ The human iris appears to be fairly resilient, and the commonest side effect is a temporary rise in intraocular pressure, with minimal disturbance of the blood/aqueous barrier. ${ }^{20} \mathrm{We}$ found it important to suppress the postlaser inflammatory response with topical steroid and to continue a low maintenance dose to suppress reopening of vessels. However, the iris is so close to the lens that transmission of heat from iris tissue to the lens is readily made. ${ }^{21}$ The lens becomes progressively pigmented with aging; thus there is an increase in absorption at short wavelengths and a greater potential for the dissipation of heat here. ${ }^{22}$ The retina may be damaged by 2 means: either an accidental direct burn, which should not occur if the beam is accurately directed; or by repetitive exposure to blue light, which has been shown to cause damage in animal eyes. ${ }^{23}$ The complications seem to be acceptable in the short-term barring the severe iris damage, but our follow-up had to be carefully super- vised, and multiple applications and visits were necessary in the very vascular lesions.

We can make suggestions on improvements in the technique so that there is added safety. The first is to make a very short focal length to the treatment beam by introducing a convex lens in front of the mirror of the slit-lamp to cause a widely diverging beam to develop after the point of focus, thereby decreasing the irradiance at deeper tissues. (Recently' a new contact lens has become available for better lasering of lipid keratopathy. It is an Abraham lens, provided by Coherent Incorporated, UK. It is basically a scleral contact lens with an added strong convex lens cemented to its surface in one quadrant. It has an antireflective coating. The convex lens makes it possible to achieve a more convergent beam and thus avoid excessive iris damage. The contact lens also provides facilities for steadying the eye during treatment. We have found it extremely easy to use.) Secondly, the cornea, lens, iris, and retina absorb more light at short wavelengths; possibly it would be better to use a blue dye for delineating the vessels and a red laser to occlude them.

What is required now is a carefully controlled longterm study. We have started such an investigation with random allocation of cases to 3 groups: $(a)$ has orally administered candicin; $(b)$ has laser treatment only; and $(c)$ has combined candicin and laser treatment.

We thank the surgeons at Moorfields Eve Hospital and the Western Ophthalmic Hospital for referring their cases. It is a pleasure to thank Mr P. West for technical help and Miss C. Smyth for secretarial assistance.

We are grateful to both the Muirhead Trust and the British National Committee for the Prevention of Blindness for the purchase of our light microscope and accessories.

\section{References}

1 Ey RC, Hughes WF, Bloome MA, Tallman CR. Prevention of corneal vascularisation. Am J Ophthalmol 1968; 66: 1118-31.

2 Lederman M. Radiotherapy of diseases of the cornea. J Fac Radiologists 1952; 4: 97-114.

3 Michaelson IC, Schreiber H. Influence of low-voltage $x$ radiation on regression of established corneal vessels. Arch Ophthalmol 1955; 56: 48-51.

4 Mandras G. Beta-therapy in ophthalmology. Arch Ophtalmol (Paris) 1956; 16: 811-6.

5 Fraser H. Nauton WJ. Treatment on non-malignant corneal conditions with radio active isotopes; a five year survey. $\mathrm{Br} J$ Ophthalmol 1961: 45: 358-64.

6 Ainslie D, Snelling MD, Ellis RE. Treatment of corneal vascularisation by $\mathrm{Sr} 90$ beta plaque. Clin Radiol 1962;13: 29.

7 Langham ME. The inhibition of corneal vascularisation by tricthylene thiophosphoramide (part 2). Am J Ophthalmol 1960); 49: 1111-25.

8 Lavergne G, Colmont IA. Comparative study of the action of thiotepa triamclinolane on corneal vascularisation in rabbits. $\mathrm{Br} J$ Ophthalmol 1964; 48: 416.

9 Mayer W. Cryotherapy in corneal vascularisation. Arch Ophthalmol 1967; 77: 637-41.

10 Duke-Elder S. Ashton N. Action of cortisone on tissue reactions 
of inflammation and repair with special reference to the eye. $\mathrm{BrJ}$ Ophthalmol 1951; 35: 695-707.

11 Cook C, MacDonald RK. Effect of cortisone on the permeability of the blood aqueous barrier to fluorescein. Br J Ophthalmol 1951; 35: 730-40.

12 Langham ME. The action of cortisone on the swelling and vascularisation of the cornea. Trans Ophthalmols Soc UK 1953; 72: 253-60.

13 Cherry PMH, Faulkner JD, Shaver RP, Wise JB, Witter SL. Argon laser treatment of corneal neovascularisation. Ann Ophthalmol 1973; 5: 911-20.

14 Read JW, Fromer C. Klintworth GK. Induced corneal vascularisation remission with argon laser therapy. Arch Ophthalmol 1975; 93: 1017-9.

15 Cherry PMH, Garner A. Corneal vascularisation treated with argon laser. Br J Ophthalmol 1979; 63: 464-72.

16 Hamilton AM. Blach RK. The technique and indications for photocoagulation in diabetic retinopathy. II. The treatment of diabetic retinopathy. Int Ophthalmol Clin 1979; 2: 85-97.
17 Marsh RJ, Ford SM. Cine photography and video recording of anterior segment fluorescein angiography. BrJ Ophthalmol 1978; 62: 657-9.

18 Apple JD, Goldberg MF, Wyhinny G. Histopathology and ultra structure of the argon laser lesion in human retinal and choroidal vasculatures. Am J Ophthalmol 1973; 75: 595-609.

19 Sliney DM, Wolbarsht ML. Effect of optical radiation on the eyes. Safety with Lasers and other Optical Sources. New York: Plenum Press, 1980: 101-59.

20 Unger WG, Brown NAP. Edwards J. Response of the human eye to laser irradiation of the iris. Br J Ophthalmol 1977; 61: 148-53.

21 Langley RK, Mortimer CB, McCulloch C. The experimental induction of cataracts by exposure to heat and light. Arch Ophthalmol 1960; 63: 473-88.

22 Lerman S. Functional Ophthalmology. New York: Macmillan, 1980: 1: 132-3.

23 Sliney DM, Wolbarsht ML. Safety standards and measurement techniques for high intensity light sources. Vision Res 1980; 20: 1133-41. 